\title{
Success factors of academic journals in the digital age
}

\author{
Milan Frederik Klus ${ }^{1}$ (D) ${\text { Alexander } \text { Dilger }^{1} \text { (D) }}$
}

Received: 14 October 2019/Accepted: 29 October 2020/Published online: 18 November 2020

(C) The Author(s) 2020

\begin{abstract}
Since the early 1990s, when digitalisation began to open new opportunities for disseminating information, many academic journals started to introduce online services. However, while some studies suggest that online availability and free access to journal articles are positively connected to the number of citations an article receives, little is known about whether being an early adopter of digital services provides journals with a (long-term) competitive advantage in times of digital change. We use data from SSCI-listed management journals to examine which journals pioneered the introduction of digital services, to what extent firstmover advantages can be identified, and which journal characteristics are associated with citation-based performance indicators. Our results show that lower ranked journals were the first to introduce digital services and were beneficiaries of the digital age. Furthermore, we find a negative correlation between general submission fees and journal performance and that the top-performing journals of our sample are those of non-commercial publishers. Our analysis of the relationship between journal performance and the provision of open access contradicts previous studies, as we find no positive correlations between performance and open access on the journal level.
\end{abstract}

Keywords Academic journals · Digitalisation · Online availability · Open access $\cdot$ Success indicators

JEL Classification I23 $\cdot$ L82 $\cdot$ L86 $\cdot$ M21 $\cdot$ O33

Alexander Dilger

alexander.dilger@uni-muenster.de

Milan Frederik Klus

milan.klus@uni-muenster.de

1 Institute for Organisational Economics, University of Münster, Scharnhorststr. 100„, 48151

Münster, Germany 


\section{Introduction}

Since the 1990s and early 2000s, more and more academic journals have offered selected content or entire issues online. With the help of modern technologies, this content can be accessed by a large number of people from any location (Lozano et al. 2012), making digitalisation a relevant aspect in the context of knowledge generation (Ding et al. 2010). Digitalisation also changes the behaviour of those who consume this content (readers), as they can search for specific topics or articles without having to search through entire journal issues (Lozano et al. 2012). As a result, readers obtain information from a variety of sources, including print journals, electronic journals, full-text databases, and e-print servers (Boyce et al. 2004), which increases the availability but also the complexity of the search process due to the multitude of possibilities (Turner 2005).

Academic journals, the main focus of our study, are still the premier format for disseminating academic articles. However, how successful a journal is in terms of its influence on the academic field largely depends on the quality of its contributions, which makes it crucial for journals to attract high-ranking authors and especially high-quality articles. Further aspects in which academic journals differ from each other and which could be relevant for explaining their success include their age (Sugimoto et al. 2013), access modalities (Borgman 2008; Sugimoto et al. 2013), costs (Beverungen et. al. 2012; Craig et al. 2007; De Groote 2008; Siar et al. 2005), and whether they demand submission fees from their contributors (Asai 2019; Chressanthis and June 1994).

Since high-quality articles are at the centre of the value proposition of academic journals, editors should also take into account the authors' behaviour. When looking for an appropriate journal to submit new research, authors typically weigh various factors, such as the journals' prestige and character (Borgman 2008). Publishing in prestigious journals is particularly important for young academics who want to establish themselves in the scientific community, while older academics often need publications in high-level journals to maintain their grants (Larivière et al. 2015) and reputations. In this context, Ayaita et al. (2019) find that younger researchers are more prolific in producing journal publications than older cohorts, which might be due to their need to establish themselves in the academic community and build a sound basis for an academic career under changed incentives. Heckman and Moktan (2020) confirm that there is a link between publishing in top journals and receiving tenure in academic economics departments, even though they criticise that a scholar's potential can hardly be judged by only a track record of publications in journals with a high impact factor. Overall, editors need to keep in mind that many academics seek to maximise the recognition of their research, for which they must choose a journal that is visible, easy for readers to access, and that publishes articles quickly (Borgman 2008). Meeting these needs is essential for academic journals to compete in an increasingly digitalised competitive environment with rapidly flowing information.

Furthermore, while authors want to publish and get cited, at the same time, they seek out others' academic contributions (Klamer and van Dalen 2002), thus playing 
roles as both contributors and consumers. The roles of these "actors" and others in the publishing process are vividly summarised by Wineburgh-Freed (2007), who describes that authors want to increase the impact of their research, commercial publishers want to increase their profits, libraries hope for relief with lower capacity requirements and cost reductions, and readers want to find literature easily and quickly.

Studies show that academic journals' online offerings are becoming more relevant. Moreover, various studies examine the customers' benefits and drawbacks to acquiring online versus print journals (Williams et al. 2006), the extent of online publications versus print publications (Mahdavi and Abedi 2014), and the user frequency of online and print journals (De Groote and Dorsch 2001; Vaughan 2003). The results overall suggest that online offerings are being used more frequently, although they do not necessarily have lower access costs.

However, less is known about which journals were the first to introduce digital services and what factors are associated with an academic journal's (long-term) performance in the digital age. This paper aims to bridge these gaps by analysing data on management journals listed in the Social Sciences Citation Index (SSCI). Building on the work by Danell et al. (1997) and more recent studies on first-mover advantages in science (e.g., Newman 2009; Sabatier and Chollet 2017), we investigate a possible link between the time of introducing digital services and an academic journal's success to see whether early adopter have a first-mover advantage. Furthermore, it is analysed whether the provision of open access (Atchison and Bull 2015; Asai 2019; Boufarss 2020; Gargouri et al. 2010; MuellerLanger and Watt 2013; Pandita 2013; Pinfield et al. 2017), the format of a journal (print, print and online, online only), and submission fees (Asai 2019; Chressanthis and June 1994) are associated with journals' scientific performance. Further explanatory variables considered include the age of a journal (Sugimoto et al. 2013) and, relating to the work by Fyfe et al. (2017), whether it belongs to a commercial publisher, a non-commercial publisher or a university press.

We argue that the digitalisation of the market of publishing scientific research is still in full swing, as evidenced not least by the fact that there are still numerous reference libraries and other large (institutional) buyers of print offerings. With a focus on the journal perspective, we aim to provide a better understanding of how digitalisation affects the market of publishing scientific research, while, at the same time, providing journals with a sound basis for making informed future-oriented decisions for their strategic development.

\section{Theoretical framework}

\subsection{The market of publishing academic research and its digitalisation}

The market of publishing academic research is based on interesting mechanisms, by which universities pay scholars to produce high-level research for academic journals (for which they also act as reviewers and editors free of charge) to repurchase this research from publishers, often commercial publishers (Beverungen et al. 2012; 
McGuigan and Russell 2008; de Zepetnek and Jia 2014). Universities, including their researchers and libraries, on the one hand and academic journals as well as their publishers on the other hand can thus be identified as the main market players, with universities and scholars acting as both producers and consumers of academic research (McGuigan and Russell 2008; Schauder 1994).

On the provider site, most academic journals are published by large commercial publishers (Bourfarss 2020; Fyfe et al. 2017). Commercial publishers charge considerably more for journals than non-commercial publishers and university presses (Bergstrom et al. 2014; Bergstrom and Bergstrom 2004; Dewatripont et al. 2007; Liebowitz 1985; Marks et al. 1991), which is not necessarily reflected in the quality of their journals (Bergstrom and Bergstrom 2004). In addition, the merging of publishers has been identified as a price-driving factor, as an increased number of journal portfolios allows prices to be determined more independently (McCabe 2001, 2002). Larivière et al. (2015) show that digitalisation has helped large publishers to increase their share of published output. According to Larivière et al. (2015), over 50\% of all academic articles published in 2013 were from the top five publishers (Reed-Elsevier, Sage Publications, Springer, Taylor \& Francis, WileyBlackwell), with over $70 \%$ of the published articles being from the social sciences. In this context, it should be noted that a combined print and electronic environment appears to be the most costly option (Turner 2005).

While it is widely accepted that journals appear online (Montgomery and King 2002; Nicholas et al. 2010; Schonfeld 2011), it is up for discussion whether they should be cheaper than their printed equivalents (Odlyzko 1998). Siar et al. (2005) stress that there is a wide range of options for pricing journals, which is challenging for both librarians and publishers. Some traditional publishers claim that switching from print to an electronic format can lead to cost savings of around 30\%, mainly through reduced printing and mailing costs (Odlyzko 1998). However, the market shows that there is little difference in the price between printed and electronic journals (Odlyzko 1998). Both formats have their cost base, with electronic journals requiring access and technology, while print journals need, amongst other things, extensive storage and shelving (Turner 2005). Montgomery and King (2002) suggest that electronic journals are more cost-effective on a per-use basis than print journals when all costs are considered.

Even though large publishers still have a lot of control over the market, increasing digitalisation has allowed new players to enter the market. These new competitors include providers such as Serial Solutions, 360 Link, and Ex Libris' SFX, which offer "online linking to full text via third-party link-resolution services" (Stuart et al. 2015, p. 52). Furthermore, there are an increasing number of digital platforms such as EBSCO, Elsevier, Ebook Library (EBL), Introtrieve, and Ingenta, which provide key benefits like a wide range of (possible) offerings, costsaving potential, and the opportunity to generate accurate user statistics (Schell et al. 2010). Electronic journal collections are becoming more widely accepted and used (Montgomery and King 2002).

Historically, online publications represent a step on a longer lasting path, as previously demonstrated by a shift from contextualised monographs to scholarly articles (Evans 2008; McCabe 2002). Especially since the 1990s, however, 
academic publishing has evolved rapidly from a paper-based system to a digital system where money is increasingly earned through licensing online access to journals or selected content (Bergstrom and Bergstrom 2004; Schell et al. 2010). As the number of articles available online increases, consumers have much less need to use reference libraries as a means to access articles (Davidson 2005). Instead, reference libraries are being replaced with online libraries that do not necessarily have to be linked to a reference library (Davidson 2005). When most journals were only available in print, many libraries offered open browsing of their collections, which has become less common in the digital age (Davidson 2005).

It should be mentioned that academic journals are not leading the way in digitalisation, but that corresponding developments are taking place across the entire media landscape. For example, Åkesson et al. (2018) shed light on the longstanding struggle of a major Swedish newspaper to switch from an old paperbased system to new digital technologies. Newspapers were also used to examine selected digitalisation-related aspects such as hyperlinking (Weber and Monge 2017). Even though the focus of this study is on academic journals, which cannot be directly compared to newspapers, we think that it makes sense for journal managers to observe the development of neighbouring industries to draw strategic conclusions for their own journal.

To identify future-oriented strategic measures for a journal, journal managers must also know the behaviour of authors and consumers of academic research and how their behaviour develops over time (Groesser 2012). Based on the ScienceDirect database, Nicholas et al. (2010) show that e-journals are not only in high demand but also that about $5 \%$ of the journals account for more than a third of all page views. This suggests that the provision of digital services can explain only part, if any, of an academic journal's attractiveness. As mentioned above, scholars act simultaneously as consumers (readers) and producers of academic research. When selecting a suitable journal for the publication of academic articles, authors pay a particular attention to the thematic consistency, quality, publication speed, and whether the journal has an open access (OA) option, whereby journals with high impact factors tend to have higher application costs (Solomon and Björk 2012). Watson et al. (2012) find that many authors are increasingly interested in publishing quickly and being listed in large databases. In particular, lesser known authors can use IT as a balancing force to increase their productivity and take advantage of an increased number of opportunities for collaboration (Ding et al. 2010), the latter being particularly helpful if senior researchers or even professors get involved (Di Vaio et al. 2012).

Furthermore, authors' reading (consuming) behaviour becomes visible through their citation behaviour, since the citations show which journals and articles are the focus of the authors' attention. Citation behaviour is used, for example, by De Groote (2008), who examines whether online journals receive more or fewer citations than print journals. As her data basis, she uses a university in Chicago with an urban and a rural campus. Her results show that authors on the urban campus cited both online and print journals to similar extents, while authors on the rural campus cited significantly fewer print journals. Since an online offer is meanwhile 
common, the strategic question for journals today is probably at which geographical locations it still makes sense to offer print editions.

Not all readers of academic literature write their own contributions, which makes their reading behaviour difficult to grasp. In this context, an indicator of reading behaviour might be the frequency of use of different sources, which is often recorded by libraries. Vaughan (2003), for example, applies usage statistics from a university library to investigate the short-term effects of online availability on the use of print journals. The results show that the use of print journals roughly halved during the observation period from 1999 to 2001 (Vaughan 2003). Williams et al. (2006) investigate the advantages and disadvantages of buying online vs. print journals and find that readers increasingly prefer access to online journals. The majority of online journal articles are now published in the two formats HTML and PDF, with the HTML format often containing hyperlinks from one article to another (Davidson 2005). These links increase the wealth of information for readers and allow them to immediately verify the accuracy of the content cited (Davidson 2005).

However, a significant disadvantage of increasing the efficiency of online searches with hyperlinking is that the results may be channelled through a filter of prevailing opinions (Evans 2008). This is supported by a study by Evans (2008), based on 34 million articles and their citations, which shows that as the prevalence of online issues increases, more recent sources are cited from a smaller number of journals and articles. Similar to internet platforms such as Facebook, an information bubble could emerge, in which opposing views are systematically excluded. A related problem is that authors preferably use frequently cited articles that come from a relatively small number of (highly ranked) journals (Evans 2008), which also can contribute to an information bubble. This becomes even more problematic for lower ranked journals, because for authors to overcome the barriers to publishing in high-ranking journals, they must base their literature review on the most frequently cited articles and play according to the rules of the market (Collin et al. 1996).

As a remedy, Beverungen et al. (2012) consider taking publishers out of the game and placing journals (which should be accessible online and provide OA options) under the direct control of the editorial board. However, they also critically note that in a world of online publications, it becomes more difficult to distinguish between journals of good and bad quality, such that the price of access to academic articles could remain a relevant indicator (Beverungen et al. 2012) and well-known publishers serve as a costly signal of good-quality journals.

\subsection{Online availability and open access}

Before discussing online availability and OA of written content in more detail, the terms should be differentiated. There are two main reasons why online availability is not necessarily synonymous with a large group of users having access to online content. The first reason is that access to the internet is a prerequisite. While this has become a rather historical aspect in many places, access to the internet was not a matter of course in the early years of digitalisation and is still not a matter of course in some parts of the world. Second, financial restrictions in the form of subscription fees play a role (Craig et al. 2007; Jeon and Rochet 2010). In most cases, they are 
covered by institutions such as universities, with which one must be connected to benefit from the licenses.

For many years now, searching for content has not required the use of electronic search terminals in libraries. Instead, meta search engines such as Google Scholar have been established, which can be used free of charge and independently of location. In this context, Brophy and Bawden (2005) stress that Google offers immediate access to a large proportion of full-text material, which puts it in serious competition with libraries. Another advantage of meta search engines is that they provide a consistent user face which makes it easier to find literature and combine the results of different search engines (Lawrence and Giles 1999). In addition, meta search engines can be used to find so-called "grey literature", which is less visible than journal articles (Goodrum et al. 2001), but can have the advantage of providing very up-to-date insights.

Regardless of the access modalities, most academic journals from various disciplines are available online (Borgman 2008), with the online version of the articles being published on average 3 months before the print version (Das and Das 2006). The amount of online content that an academic journal offers varies widely, where younger journals are more often only available in the online format while older journals sometimes only put a selection of older issues online (Borgman 2008). The fact that there are still print-only journals may be because of economic reasons. For example, third-party providers such as the subscription journal archiving service Muse can offer their members OA to online issues (Davidson 2005). If a user group belongs to the customer base of a journal, this can lead customers to cancel their subscriptions (Davidson 2005). Thus, when readers have no incentive to pay for an individual subscription, because they can use full online access through institutional providers (Davidson 2005), some journals may find it economically beneficial to offer no online content and retain their print-only status.

In addition to economic considerations, academic journals have an interest in obtaining a high number of citations to increase their visibility and citation-based success indicators like the impact factor or immediacy index. While Lawrence (2001) finds a positive correlation between online availability and citation rates, Anderson et al. (2001) show that online-only peer-reviewed content is cited at an average rate, so that online availability alone does not seem sufficient for explaining increased citation rates. In this context, a closer look at the topic of OA seems reasonable, since free access to written content might be a relevant component in explaining citation frequencies.

OA is a noteworthy development (Boufarss 2020) that influences the workflow in academic journals, their credibility, indexability, and quality (Gasparyan et al. 2013). OA can be offered by academic journals, either generally or for selected articles often depending on a fee by the authors, or by authors themselves who give free access on the internet to a version of their article (Björk et al. 2010). Demanding fees from authors enables journals to offer articles free of charge (Jeon and Rochet 2010), which increases their likelihood of getting read and cited. Laakso et al. (2011) show a rapid increase in OA publications from 1993 to 2009, which can be divided into OA's pioneering years (1993-1999), innovation years (2000-2004), and consolidation years (2005-2009). According to Davidson (2005), the OA 
movement is now generally committed to making all articles freely available online 6 months after their publication. Björk et al. (2010) show that OA already has a significantly positive effect on the accessibility of academic literature.

In addition to accessibility, the influence of OA on the citation rates of academic publications is of interest (Borgman 2008). Bernius and Hanauske (2009) suggest that if two authors publish articles of similar quality, OA leads to increased citations as OA articles are on average read and downloaded more frequently than charged articles. Eysenbach (2006) confirms that OA articles are more quickly noticed and cited than non-OA articles in the same journals. However, Gaulé and Maystre (2011) doubt the result of Eysenbach (2006) and other cross-sectional studies and address probable sources of endogeneity. They conclude that high-level articles are more likely to be submitted as OA articles to hybrid journals that offer an OA option. Pinfield et al. (2017) point in a similar direction as they find a positive correlation between a journal's price and its impact factor.

\subsection{Success indicators of academic journals}

When considering the success of academic journals, economic success (e.g., number of subscribers) should be differentiated from scientific success (e.g., number of citations), whereby both types of success are probably correlated. We focus our study on the scientific success of academic journals, for which we use the wellestablished practice of citation analysis (Azar and Brock 2008; Magri and Solari 1996; Todorov and Glänzel 1988). In this context, citations are used to measure the recognition of both individual publications and journals (Borgman 2008).

Even though citation analysis is fundamentally based on an error-prone technical matching process in which citing sources and cited sources are identified (van Raan 2005), citation-based measures such as the impact factor and immediacy index (see Table 1 below) are widely used to evaluate scientific output (Abramo et al. 2019; Borokhovich et al. 1999; Groesser 2012; Krell 2012; Thelwall 2012). According to Krell (2012), the impact factor is particularly common in journal-focused analyses, which is reasonable, since the number of citable items is taken into account in the calculation (see Table 1). However, Atchison and Bull (2015) point out that the impact factor has limitations, e.g., that it can be strongly influenced by a small number of frequently cited articles. To alleviate this problem, it is advisable to use the average value of the impact factor over, for example, a 5-year period. Furthermore, Todorov and Glänzel (1988) stress that citation-based measures strongly depend on the citation practices established in a field, so that only journals within a specific field should be compared.

The Social Sciences Citation Index (SSCI) is an established source for the collection of citation-based success indicators, as it makes data available on an annual level and differentiated by thematic fields (Borokhovich et al. 1999; Todorov and Glänzel 1988). Respective data can be retrieved, for example, from Thomson Reuter's Web of Science (Azar and Brock 2008; Borgman 2008). 
Table 1 List of variables

\begin{tabular}{|c|c|}
\hline Variable name & Definition \\
\hline \multicolumn{2}{|l|}{$\begin{array}{l}\text { Dependent } \\
\text { variables }\end{array}$} \\
\hline $\begin{array}{l}\text { Immediacy } \\
\text { index }\end{array}$ & $\begin{array}{l}\text { The immediacy index is the average number of times articles in a journal are cited in } \\
\text { the year they are published }\end{array}$ \\
\hline Impact factor & $\begin{array}{l}\text { The impact factor is defined as all citations in the current year to scholarly items by a } \\
\text { journal published in the previous two years, divided by the total number of } \\
\text { scholarly items (these comprise articles, reviews, and proceedings papers) } \\
\text { published in the journal in the previous two years }\end{array}$ \\
\hline \multicolumn{2}{|l|}{$\begin{array}{l}\text { Explanatory } \\
\text { variables }\end{array}$} \\
\hline $\begin{array}{l}\text { Access } \\
\text { category }\end{array}$ & $\begin{array}{l}\text { Categorical variable equal to } 0 \text { if no open access is being offered at all, equal to } 1 \text { if } \\
\text { all issues and articles are freely available, and equal to } 2 \text { if open access is provided } \\
\text { only for selected issues or articles }\end{array}$ \\
\hline Digital services & $\begin{array}{l}\text { Categorical variable equal to } 1 \text { if the journal is amongst the first to introduce digital } \\
\text { services (before 1996), equal to } 2 \text { if it is a follower (1996-2000), and equal to } 3 \text { if } \\
\text { it is a late mover (2001-2016) }\end{array}$ \\
\hline First edition & The year in which a journal published its first edition \\
\hline $\begin{array}{l}\text { Journal } \\
\text { category }\end{array}$ & $\begin{array}{l}\text { Categorical variable equal to } 1 \text { if it is an online journal, equal to } 2 \text { if the journal is } \\
\text { available in both print and online, and equal to } 3 \text { if it is a print-only journal }\end{array}$ \\
\hline $\begin{array}{r}\text { Publisher } \\
\text { category }\end{array}$ & $\begin{array}{l}\text { Categorical variable equal to } 1 \text { if a journal has a commercial publisher, equal to } 2 \text { if it } \\
\text { has a non-commercial publisher, and equal to } 3 \text { if the publisher is a university } \\
\text { press }\end{array}$ \\
\hline $\begin{array}{l}\text { Submission } \\
\text { fees }\end{array}$ & $\begin{array}{l}\text { Categorical variable equal to } 0 \text { if the journal has no submission fees at all, equal to } 1 \\
\text { if a submission fee is always required, and equal to } 2 \text { if a fee has to be paid only if } \\
\text { the authors want their article to be freely available on the internet }\end{array}$ \\
\hline
\end{tabular}

\section{Empirical investigation}

\subsection{Hypotheses}

To measure how online availability and $\mathrm{OA}$ are associated with citation-based performance indicators, previous studies have focused on the article level or single journal issues without investigating journals overall (McCabe and Snyder 2015). We contribute to the existing literature by conducting a journal-level analysis with a focus on the (long-term) citation-based performance in the digital age.

We start by investigating who pioneered the introduction of digital services and whether it was advantageous for journals to be a first mover. This aspect is relevant as more and more journals have introduced digital services over time, such that this is not a unique selling proposition in the long run. Furthermore, online availability is not synonymous with a large group of users having access to this content (see Sect. 2.2. above). Digital services were not part of the traditional business model of established (top) journals, which gives reason to believe that it was the smaller and less established journals in particular that first introduced online services. Accordingly, we formulate our first hypothesis: 
H1 The lower the performance of journals, the more likely they are to have pioneered the introduction of digital services.

However, even if the group of today's top journals is not necessarily associated with an early introduction of digital services, it is possible that early provision of digital services helped less successful journals to increase their performance. This is supported by the fact that early movers laid the foundation for a future-ready digital strategy, whereas established (top) journals only slowly started to change their traditional business model. Consequently, there is reason to believe that early mover journals have been able to reduce the performance gap with their established competitors over time. Therefore, our second hypothesis is as follows:

H2 The lower the performance of journals, the more digitalisation has helped them narrow the performance gap with their competitors.

Given that not only digital services but also OA are not part of the traditional business model of established academic journals and that many scholars have institutional access to charged content, we expect that OA journals are not amongst today's top performers, and we formulate our third hypothesis:

H3 If journals provide paid access, then they likely perform better than OA journals.

Considering that free access to highly published contributions has become increasingly valuable in the digital age and fees for an OA option have become more and more common, we follow Gaulé and Maystre (2011) and expect a positive correlation between fees for an OA option and journal performance. Contrary to the results provided by Chressanthis and Chressanthis (1994), we also expect that the willingness to pay general submission fees is low, especially for high-level research. Accordingly, we formulate our fourth hypothesis:

H4 If journals do not charge submission fees or only charge for an OA option, then they likely perform better than journals that charge general submission fees.

Finally, although the market of publishing scientific research seems to be dominated by a small number of large commercial publishers (see Sect. 2.1), some academic associations publish older journals of higher reputation. In a way, commercial publishers cannot earn that much when they operate in direct competition with other publishers that lack the profit motif, such that the former fill the spots left by the later. However, there are many spots to fill with more and more scholars and written articles. Our fifth hypothesis is as follows:

H5 If a journal is from a non-commercial publisher, then it likely performs better than journals from commercial publishers.

\subsection{Data}

Our research is based on the 194 SSCI-listed journals in the field of management in 2016. We focus our investigation on the management discipline, because it provides a fertile field for measuring digitalisation effects (McCabe and Snyder 2015) and is 
in line with our research focus. "Harder" scientific disciplines may be less interesting for studying digitalisation effects, as they are often funded with large grants, and the access costs are comparatively low (McCabe and Snyder 2015). Scientific indicators have been documented for many years, for example, in the Science Citation Index (SCI) back to 1900, the Social Sciences Citation Index (SSCI) back to 1956, and the Arts and Humanities Citation Index (A\&HCI) back to 1975 (Borgman 2008), and are now available over the Web of Science by Thomson Reuters. The Scimago Journal and Country Rank database was used, for example, by Watson et al. (2012), and the Scimago Journal Rank (SJR) indicator has been recommended by González-Pereira et al. (2010) for measuring the scientific prestige of a journal. However, these data can only be traced back to 1999. Since the shift from print to electronic format took place mainly in the 1990s, an adequate analysis requires data from earlier years.

To establish a mostly complete record for the period from 1989 to 2016, we supplemented the data from Thomson Reuters and Scimago with hand-collected data from Journal Citation Reports for social science journals stored in German university archives. To obtain data on the shift from print to digital formats, we investigated the journals' archives. The changeover from print to online was identified by examining up to which year scanned articles were uploaded instead of digital formats. The first year in which a machine-generated digital format was made available instead of a scanned article was taken as the changeover year of the respective journal. A missing value was entered if we could not get access to the contents of a journal or if it was not clearly identifiable whether it was a machinegenerated digital article or a scan. Since, in many cases, it was not possible to determine retrospectively from when OA was offered (if at all), we decided to use a time-invariant categorical variable indicating the access modalities. Setting a date based on the content available today could easily lead to biases, as articles could have been made freely available retroactively at a later date. The same applies to the variable submission fees, where it is similarly difficult to determine time variances retrospectively. Data on submission fees were obtained from the journals' websites, where this information is typically included in the authors' guidelines.

Table 1 shows a list of the variables collected, including their definitions. The respective summary statistics (considering the whole period) are presented in Table 2, which are restricted to the year 2016 in Table 3.

\subsection{Method}

We follow Borokhovich et al. (1999) and use both the impact factor and the immediacy index as our dependent variables. A particular focus is on the impact factor, as it is a relative measure taking into account the number of citable items (see Sect. 2.3). It should be noted that the total number of citations shows fluctuations, as journals are added to and removed from the journal list over time. This also influences the citation-based impact factor and the immediacy index, whereby the article-based calculation mitigates the effect. In case of the impact factor, the effect is additionally mitigated by the 2-year reference base. 
Table 2 Summary statistics (whole period)

\begin{tabular}{|c|c|c|c|c|c|c|c|c|}
\hline & Mean & $\begin{array}{l}\text { SD } \\
\text { (Overall) }\end{array}$ & $\begin{array}{l}\text { SD } \\
\text { (Between) }\end{array}$ & $\begin{array}{l}\text { SD } \\
\text { (Within) }\end{array}$ & Min & $\operatorname{Max}$ & $\begin{array}{l}\text { No } \\
\text { journals }\end{array}$ & $\begin{array}{l}\text { No. } \\
\text { Obs }\end{array}$ \\
\hline \multicolumn{9}{|l|}{ Dependent variables } \\
\hline Immediacy index & 0.28 & 0.32 & 0.21 & 0.26 & 0.01 & 3.70 & 194 & 2189 \\
\hline Impact factor & 1.38 & 1.23 & 0.97 & 0.80 & 0.02 & 11.12 & 192 & 2523 \\
\hline \multicolumn{9}{|l|}{ Explanatory variables } \\
\hline \multicolumn{9}{|l|}{ Access category } \\
\hline No OA & 0.09 & 0.28 & 0.28 & 0.00 & 0 & 1 & 176 & 4928 \\
\hline OA (general) & 0.04 & 0.21 & 0.21 & 0.00 & 0 & 1 & 176 & 4928 \\
\hline $\begin{array}{l}\text { OA for selected } \\
\text { content }\end{array}$ & 0.87 & 0.34 & 0.34 & 0.00 & 0 & 1 & 176 & 4928 \\
\hline \multicolumn{9}{|l|}{ Digital services } \\
\hline First mover & 0.08 & 0.28 & 0.28 & 0.00 & 0 & 1 & 169 & 4732 \\
\hline Follower & 0.53 & 0.50 & 0.50 & 0.00 & 0 & 1 & 169 & 4732 \\
\hline Late mover & 0.39 & 0.49 & 0.49 & 0.00 & 0 & 1 & 169 & 4732 \\
\hline First edition (year) & 1985.48 & 16.30 & 16.34 & 0.00 & 1917 & 2014 & 186 & 5208 \\
\hline \multicolumn{9}{|l|}{ Journal category } \\
\hline Online & 0.02 & 0.15 & 0.18 & 0.00 & 0 & 1 & 171 & 3976 \\
\hline Online and print & 0.68 & 0.47 & 0.24 & 0.42 & 0 & 1 & 171 & 3976 \\
\hline Print & 0.30 & 0.46 & 0.21 & 0.42 & 0 & 1 & 171 & 3976 \\
\hline \multicolumn{9}{|l|}{ Publisher category } \\
\hline $\begin{array}{l}\text { Commercial } \\
\text { publisher }\end{array}$ & 0.87 & 0.34 & 0.34 & 0.00 & 0 & 1 & 189 & 5292 \\
\hline $\begin{array}{l}\text { Non-commercial } \\
\text { publisher }\end{array}$ & 0.05 & 0.21 & 0.21 & 0.00 & 0 & 1 & 189 & 5292 \\
\hline University press & 0.08 & 0.28 & 0.28 & 0.00 & 0 & 1 & 189 & 5292 \\
\hline \multicolumn{9}{|l|}{ Submission fees } \\
\hline No fees & 0.16 & 0.37 & 0.37 & 0.00 & 0 & 1 & 163 & 4564 \\
\hline General fees & 0.03 & 0.17 & 0.17 & 0.00 & 0 & 1 & 163 & 4564 \\
\hline Fees for OA & 0.81 & 0.39 & 0.39 & 0.00 & 0 & 1 & 163 & 4564 \\
\hline
\end{tabular}

Furthermore, because Magri and Solari (1996) showed that a substantial heterogeneity in citations exists between journals over time, which was revealed by a considerable asymmetry of the frequency distributions, we control for this phenomenon by conducting a journal-level analysis. According to McCabe and Snyder (2015), many previous studies have overestimated the effect of online availability or OA on citations, because they did not control for the journal quality.

To measure the connection between our journal-level explanatory variables and the journals' performance, we run two separate regressions, one with the impact factor and another with the immediacy index as the dependent variable. Since our explanatory variables are time invariant (at least in our data) and, therefore, not suitable for fixed effects models, we conduct a cross-sectional analysis for the year 
Table 3 Summary statistics (year 2016)

\begin{tabular}{|c|c|c|c|c|c|}
\hline & Mean & SD & Min & $\operatorname{Max}$ & No journals \\
\hline \multicolumn{6}{|l|}{ Dependent variables } \\
\hline Immediacy index (5-year mean) & 0.33 & 0.25 & 0.03 & 1.39 & 194 \\
\hline Impact factor (5-year mean) & 1.73 & 1.35 & 0.06 & 8.01 & 192 \\
\hline \multicolumn{6}{|l|}{ Explanatory variables } \\
\hline \multicolumn{6}{|l|}{ Access category } \\
\hline No OA & 0.08 & 0.28 & 0 & 1 & 176 \\
\hline OA (general) & 0.05 & 0.21 & 0 & 1 & 176 \\
\hline OA for selected content & 0.87 & 0.34 & 0 & 1 & 176 \\
\hline \multicolumn{6}{|l|}{ Digital services } \\
\hline First mover & 0.08 & 0.28 & 0 & 1 & 169 \\
\hline Follower & 0.53 & 0.50 & 0 & 1 & 169 \\
\hline Late mover & 0.39 & 0.49 & 0 & 1 & 169 \\
\hline First edition (year) & 1985.48 & 16.34 & 1917 & 2014 & 186 \\
\hline \multicolumn{6}{|l|}{ Journal category } \\
\hline Online & 0.04 & 0.19 & 0 & 1 & 169 \\
\hline Online and print & 0.96 & 0.19 & 0 & 1 & 169 \\
\hline \multicolumn{6}{|l|}{ Print } \\
\hline \multicolumn{6}{|l|}{ Publisher category } \\
\hline Commercial publisher & 0.87 & 0.34 & 0 & 1 & 189 \\
\hline Non-commercial publisher & 0.05 & 0.21 & 0 & 1 & 189 \\
\hline University press & 0.08 & 0.28 & 0 & 1 & 189 \\
\hline \multicolumn{6}{|l|}{ Submission fees } \\
\hline No fees & 0.16 & 0.37 & 0 & 1 & 163 \\
\hline General fees & 0.03 & 0.17 & 0 & 1 & 163 \\
\hline Fees for $\mathrm{OA}$ & 0.81 & 0.39 & 0 & 1 & 163 \\
\hline
\end{tabular}

2016. Due to the volatility of the citation-based dependent variables, we calculated the 5-year means (2012-2016) of the impact factor and immediacy index per journal and used these for the regressions. Besides a variable (digital services) indicating the introduction of digital services ( $\mathrm{H} 1$ and H2), we follow Watson et al. (2012) for the selection of our explanatory variables: We include a variable (access category) indicating whether a journal provides $\mathrm{OA}$ to all or selected content $(\mathrm{H} 3)$, a variable (submission fees) indicating whether a journal charges submission fees (H4), and a variable (publisher category) containing information about the respective publisher (H5). We additionally control for the journals' age, measured by the year of their first published edition (first edition), and whether the journal is online, print or both (journal category).

The baseline equation for our regression analysis is: 
Success $_{i}=\alpha+\operatorname{access}_{\text {category }} \beta_{1}+$ digital services $_{i} \beta_{2}+$ first edition $_{i} \beta_{3}$

+ journal category $_{i} \beta_{4}+$ publisher category $_{i} \beta_{5}$

+ submission fees $_{i} \beta_{6}+\mu_{i}$

where Success $_{i}$ is the dependent variable representing either the 5-year mean impact factor (2012-2016) of journal $i$ or its 5-year mean immediacy index, and $\mu_{i}$ is the error term.

As the explanatory variables of interest are time invariant, we additionally apply descriptive analyses to examine our hypotheses and generate insights into the journals' performance over time. For this purpose, we use illustrations in which we show the journals' impact factor over time, differentiated by the journal categories defined in our explanatory variables (see Sect. 6.1).

\section{Results}

\subsection{Descriptive results}

In the first step of our descriptive analysis, we examine the introduction of digital services into the field of academic journals, for which we distinguish between print journals, journals with combined print and online services, and online journals. Figure 1 shows the number of journals offering services of the categories "online

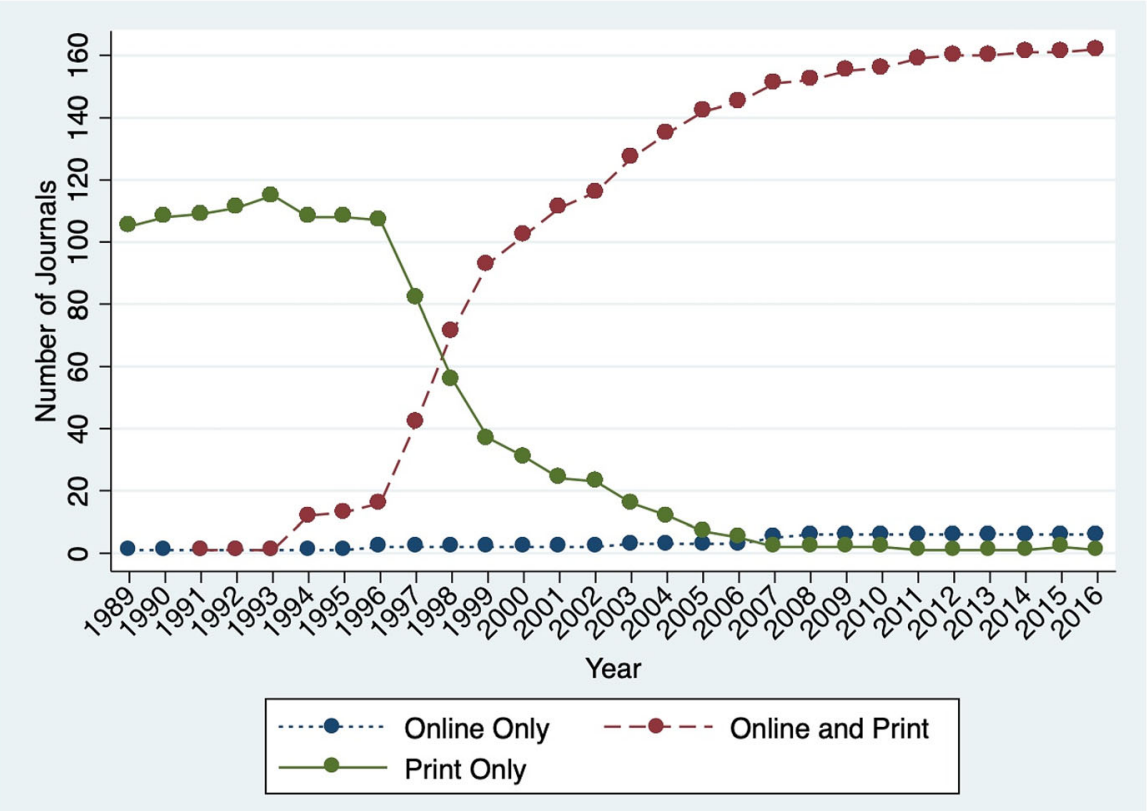

Fig. 1 Publication types of journals over time 
only", "online and print", and "print only" over time. It can be observed that the first journals began introducing online services in the early 1990s. There was a particularly sharp increase in the years after 1996, which levelled off slowly from the 2000s onwards. A contrary trend can be observed in "print only" services, which declined rapidly from 1996 onwards and almost disappeared in the course of the 2000s, which is in line with De Groote (2008) and Vaughan (2003). In our sample, the group of journals that offer their content exclusively online is small.

As a first step to investigate whether lower performing journals were the early movers (as stated in hypothesis H1), we defined three groups of journals based on the mean impact factor relative to all observed journals in the SSCI, which is a positive selection by itself, because it excludes, for example, predatory journals that are often OA (and mostly take publication fees instead of submission fees): lower class ( $\leq 25$ percentile), middle class (between 25 and 75 percentiles), and upper class ( $\geq 75$ percentile). We created the journal classes based on the average impact factor of the entire period to avoid multiple counting of journals with significant changes in the impact factor over time. Figure 2 shows how many journals of the three categories introduced online services in each year of our observation period. It shows that most journals in all three categories have offered digital services since around 1998. The earliest date for online services in our sample was 1989 for a lower class journal, followed by one middle class in 1991. Accordingly, Fig. 2 indicates descriptively that lower and middle class journals indeed pioneered the introduction of digital services, whereas the number of upper class journals offering

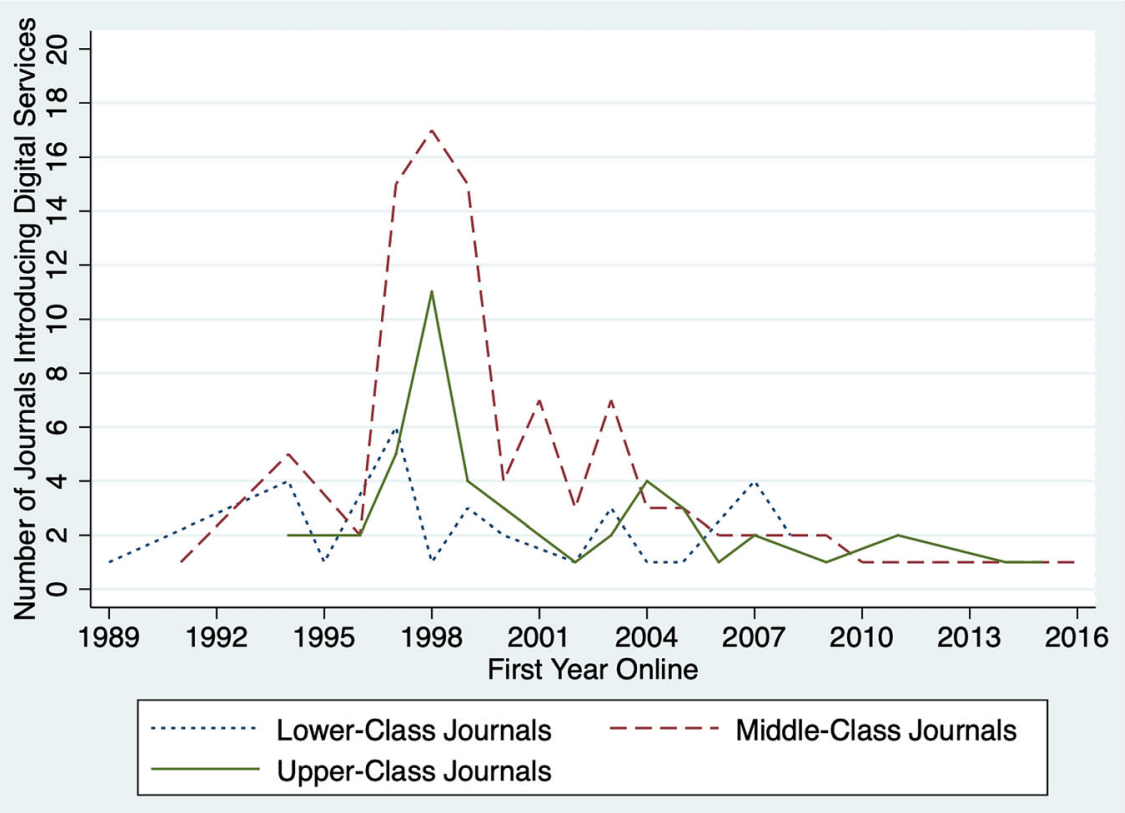

Fig. 2 Number of journals introducing digital services by journal class 
online services began to rise somewhat later. However, as there are relatively few data points for this period, the robustness and generalisability are limited.

To determine whether early introduction of digital services helped lower and middle class journals to reduce their performance gap with the top journals (H2), we created three journal categories: First movers (introduction of online services before 1996), followers (introduction of online services between 1996 and 2000), and late movers (introduction of online services from 2001), and we analysed their impact factors (see Fig. 3). The mean impact factor over time shows no discernible differences in the time trend of first movers, followers, and late movers. However, the group of early movers consists mainly of lower and middle class journals, while late movers seem to be the top performers, which supports our hypothesis H1. The followers group initially had a mean impact factor between the first movers and the late movers. This corresponds to Fig. 2. However, the initial top performers could not maintain their lead over time. Especially, since the beginning of the 2000s, the first movers increased their mean impact factor significantly, while the followers reached or even overtook the impact of the late movers, which is in line with our hypothesis H2. To examine to what extent Fig. 3 could be distorted by a very different number of journals within the three categories, we add Table 4 with the corresponding frequencies. This reveals that the first-mover category comprises a total of 14 journals, of which only one is an upper-class journal. This has to be taken into account when interpreting the results.

The relationship between the journals' mean impact factor and their access modalities over time is shown in Fig. 4. A total of 17 journals with paid access,

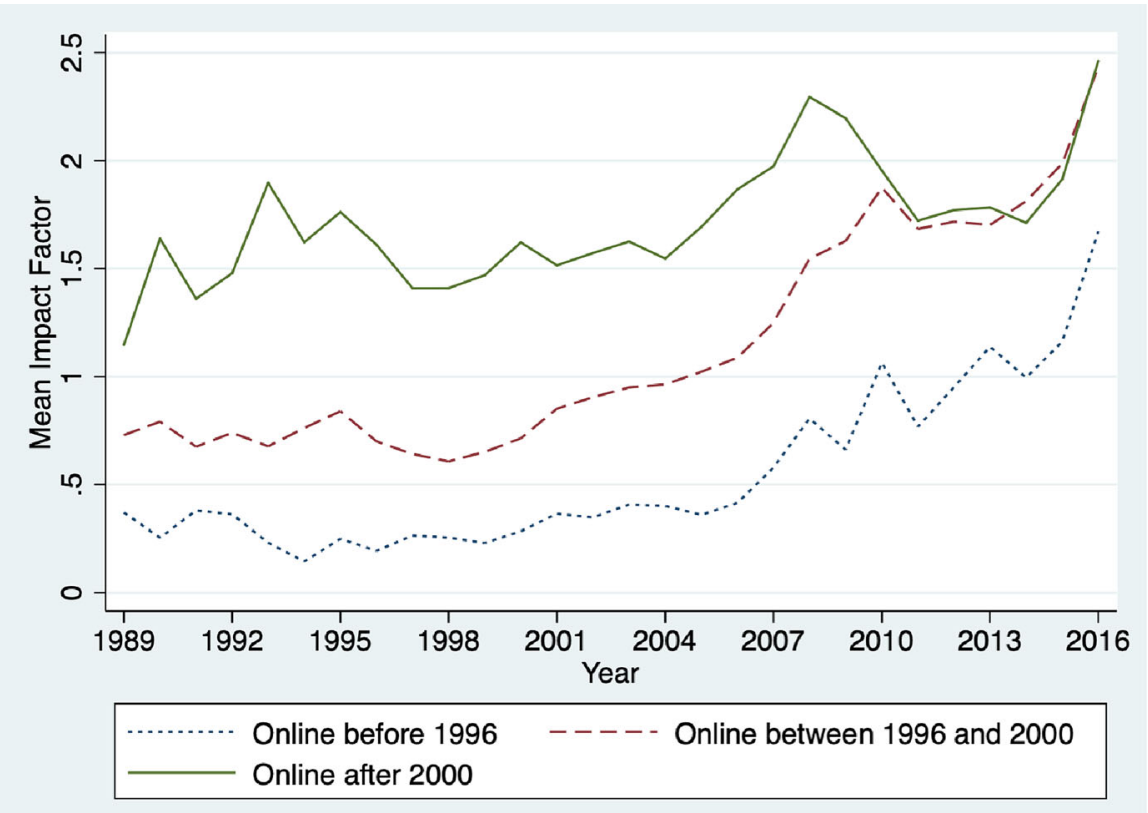

Fig. 3 Mean impact factor of journals by introduction of online services 
Table 4 Matrix of journal classes and first online services

\begin{tabular}{llll}
\hline & Online before 1996 & Online between 1996 and 2000 & Online after 2000 \\
\hline Upper class journals & 1 & 23 & 19 \\
Middle class journals & 7 & 55 & 33 \\
Lower class journals & 6 & 12 & 13 \\
\hline
\end{tabular}

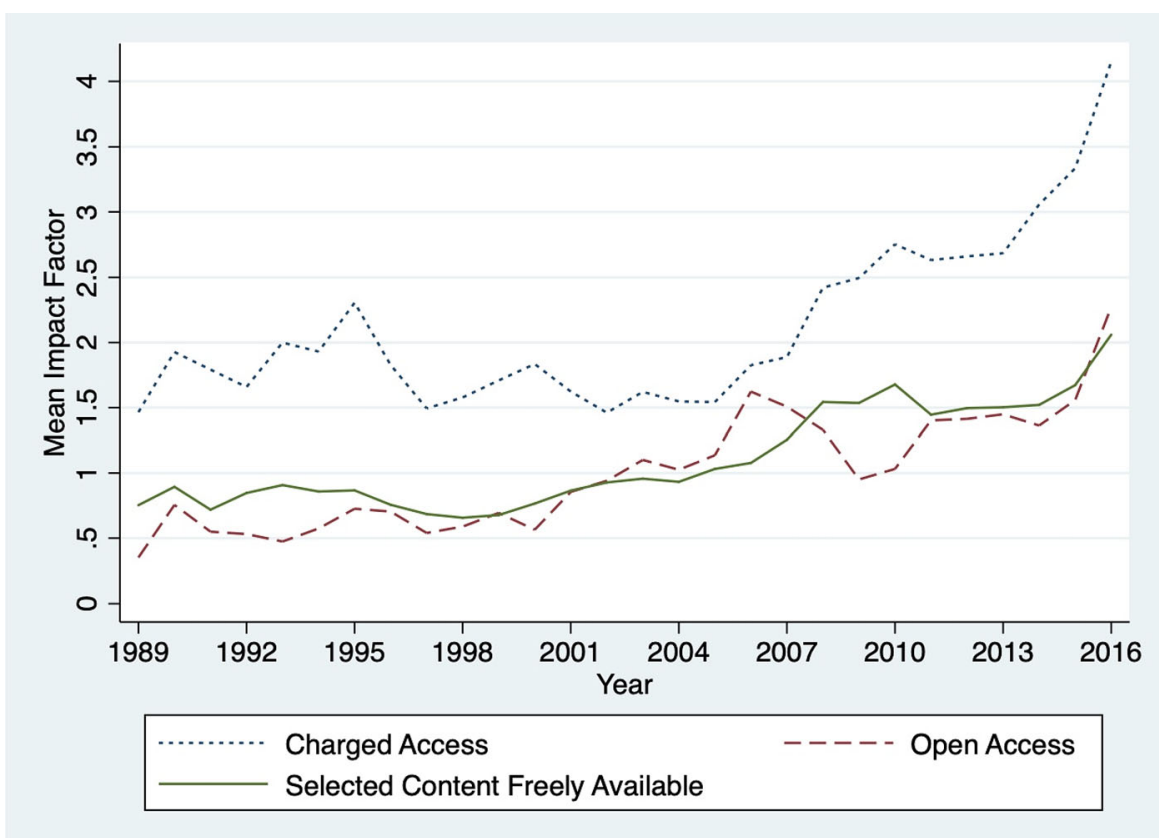

Fig. 4 Mean impact factor by access category

eight with general OA and 153 with OA for selected content are included. The high number of journals offering OA for selected content must be taken into account when interpreting the results. Accordingly, it can be observed that journals with charged access stand out positively in accordance with hypothesis H3.

Figure 5 shows the mean impact factor of journals that charge general submission fees, journals that charge fees for an OA option, and journals that do not charge submission fees. Our sample includes 25 journals without submission fees, five journals with submission fees, and 133 journals that charge fees for an OA option. Journals not charging submission fees have the highest mean impact factor over time. However, Fig. 4 also shows that journals charging fees for an OA option have developed very positively and, at the end of the observation period, are almost on par with journals not charging any fees. On average, journals levying submission fees show the lowest impact factor in accordance with hypothesis H4. However, data for this category are retrievable only from 1997 onwards. 


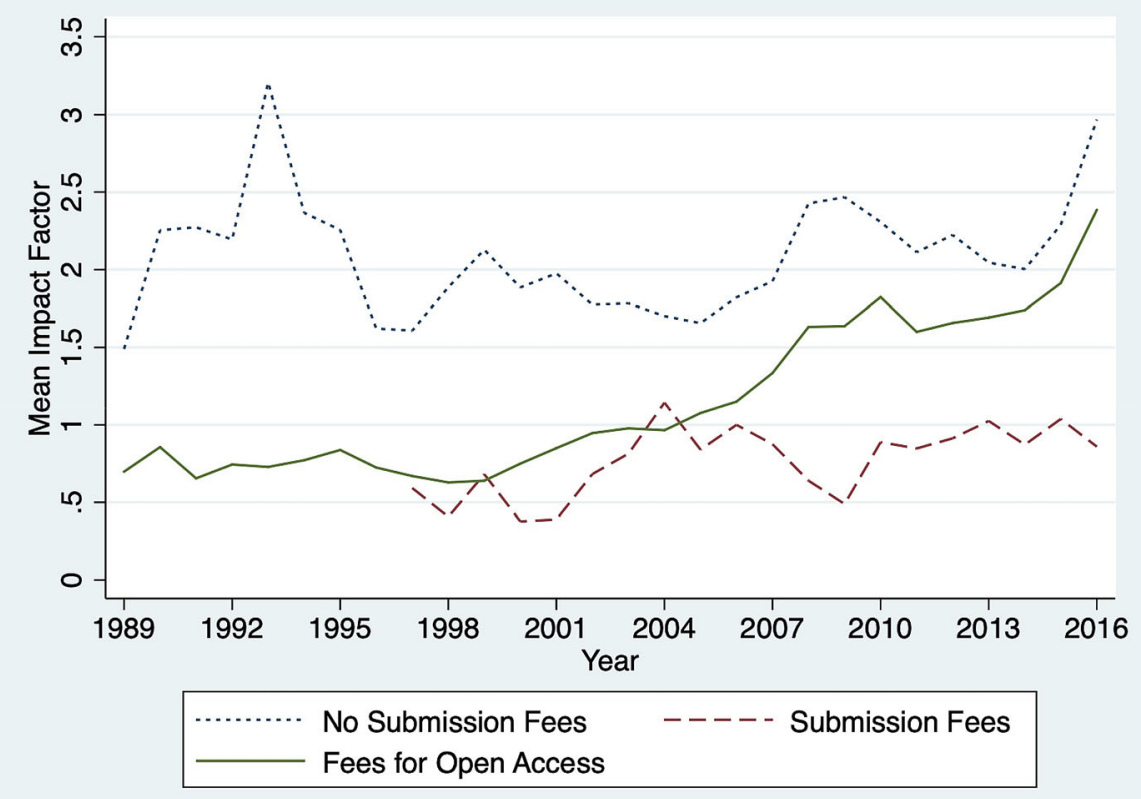

Fig. 5 Mean impact factor by submission fees

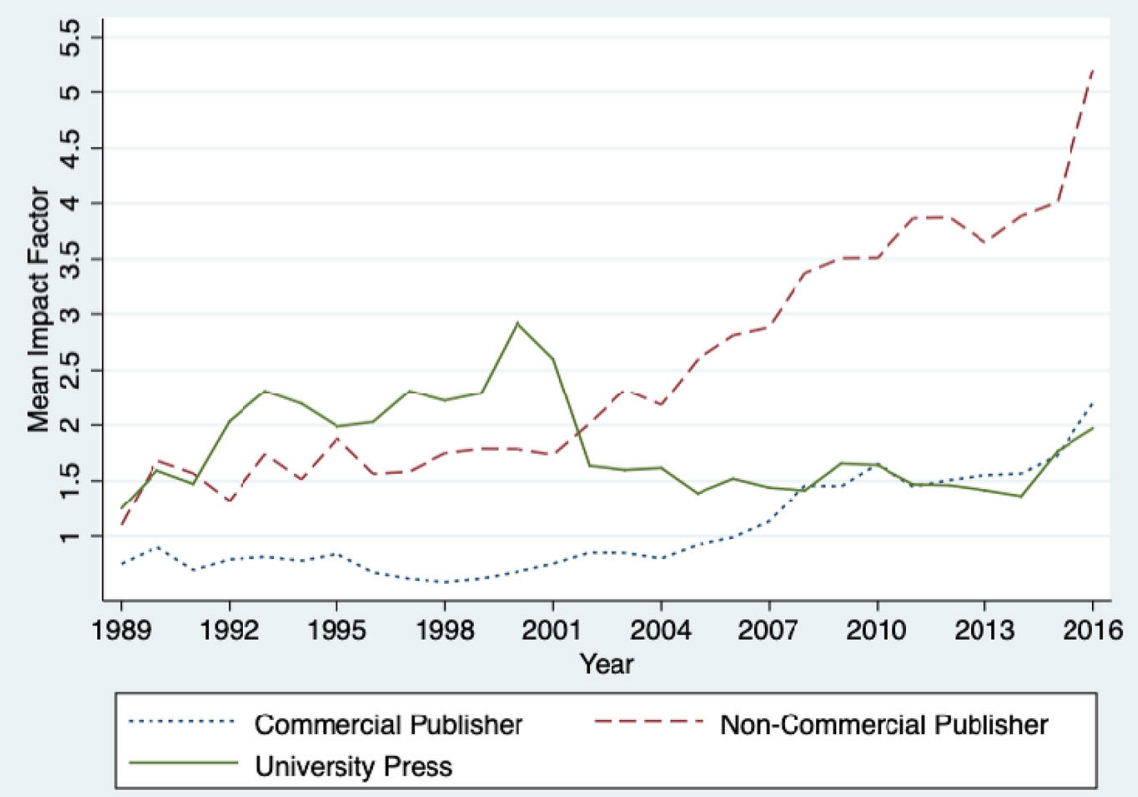

Fig. 6 Mean impact factor by publisher category 
Figure 6 shows the mean impact factor of journals whose publishers are commercial, non-commercial, or university presses (H5). In total, our sample includes 149 journals associated with commercial publishers, 9 with noncommercial publishers (excluding university presses), and 12 with university presses. When interpreting the results, these different numbers must be taken into account. While journals associated with university presses where the top performers until around 1999, their mean impact factor decreased considerably in the following years and fell below the mean impact factor of journals associated with (other) noncommercial publishers in 2002. Interestingly, the journals linked to commercial publishers have generally had a relatively low mean impact factor, in line with our hypothesis H5, but in 2008, this increased above the performance of journals related to university presses.

Looking at possible connections between journals charging fees for accessing or submitting articles and type of publisher (commercial, non-commercial, or university press), it appears that not only commercial but also non-commercial publishers and university presses are associated with journals that charge fees. Accordingly, a separate analysis of the relationship between the journals' performance and publishers is necessary and cannot be derived from Fig. 6 alone.

\subsubsection{Regression results}

In addition to our descriptive analysis, we use regression analyses to examine the connection between our explanatory variables and the journals' academic success indicators. Table 5 shows the results of two regression models with the 5-year mean (2012-2016) impact factor and immediacy index as the dependent variables. Summary statistics of the journals included in the regressions are summarised in Table 6 in the Appendix.

As can be seen from Table 5, there are significantly positive coefficients for followers and late movers in both models, indicating that they perform better than early movers (which form the reference category). Accordingly, this result supports our hypothesis $\mathrm{H} 1$ and shows that lower performing journals pioneered the introduction of digital services. However, the results of mean-comparison tests indicate no statistically significant difference between the performance of followers and late movers ( $p$ value 0.91 for impact factor, $p$ value 0.63 for immediacy index). Contradicting previous studies, we find no significant correlations between the provision of $\mathrm{OA}$ and performance indicators on the journal level. Accordingly, our hypothesis $\mathrm{H} 3$ cannot be evidenced based on the regression results. However, we find significantly positive coefficients for journals charging no submission fees or for OA only, which supports our hypothesis H4. Accordingly, these journals perform better than those charging general submission fees (which form the reference category in our regressions). A mean-comparison test additionally reveals, at least when considering the five-year mean impact factor, that journals without submission fees perform better than those charging fees for an OA option ( $p$ value 0.01 ). However, we find no statistically significant difference based on the 5-year mean immediacy index ( $p$ value of 0.14 ). Our regression results show that journals that offer online and print services perform better than online journals, whereby the 
Table 5 Regression results

\begin{tabular}{|c|c|c|}
\hline & (1) & (2) \\
\hline Dependent variables & $\begin{array}{l}\text { 5-year mean impact } \\
\text { factor }\end{array}$ & $\begin{array}{l}\text { 5-year mean immediacy } \\
\text { index }\end{array}$ \\
\hline \multicolumn{3}{|l|}{ Explanatory variables } \\
\hline \multicolumn{3}{|l|}{ Access category } \\
\hline \multirow[t]{2}{*}{ OA (general) } & -0.357 & -0.032 \\
\hline & $(0.889)$ & $(0.127)$ \\
\hline \multirow[t]{2}{*}{ OA for selected content } & -0.644 & -0.089 \\
\hline & $(1.003)$ & $(0.127)$ \\
\hline \multicolumn{3}{|l|}{ Digital services } \\
\hline \multirow[t]{2}{*}{ Follower (1996-2000) } & $0.758 * * *$ & $0.159 * * *$ \\
\hline & $(0.212)$ & $(0.049)$ \\
\hline \multirow[t]{2}{*}{ Late mover (2001-2016) } & $0.697 * * *$ & $0.132 * * *$ \\
\hline & $(0.213)$ & $(0.050)$ \\
\hline \multirow[t]{2}{*}{ First edition (year) } & $-0.013^{*}$ & -0.001 \\
\hline & $(0.008)$ & $(0.001)$ \\
\hline \multicolumn{3}{|c|}{ Journal category (reference category: online) } \\
\hline \multirow[t]{2}{*}{ Online and print } & $0.881 * * *$ & $0.114^{*}$ \\
\hline & $(0.223)$ & $(0.067)$ \\
\hline \multicolumn{3}{|c|}{$\begin{array}{l}\text { Publisher category (reference category: } \\
\text { commercial publisher) }\end{array}$} \\
\hline \multirow[t]{2}{*}{ Non-commercial } & $1.817^{*}$ & $0.271^{*}$ \\
\hline & $(1.063)$ & $(0.154)$ \\
\hline \multirow[t]{2}{*}{ University press } & -0.725 & -0.038 \\
\hline & $(0.446)$ & $(0.075)$ \\
\hline \multicolumn{3}{|c|}{ Submission fees (reference category: general fees) } \\
\hline \multirow[t]{2}{*}{ No fees } & $1.551 * * *$ & $0.266 * * *$ \\
\hline & $(0.584)$ & $(0.083)$ \\
\hline \multirow[t]{2}{*}{ Fees for $\mathrm{OA}$} & $1.413 * *$ & $0.273 * * *$ \\
\hline & $(0.618)$ & $(0.090)$ \\
\hline \multirow[t]{2}{*}{ cons } & $25.827 *$ & 1.684 \\
\hline & $(15.052)$ & $(2.755)$ \\
\hline$R^{2}$ & 0.235 & 0.101 \\
\hline$P$ & 0.000 & 0.000 \\
\hline$N$ & 147 & 147 \\
\hline
\end{tabular}

This table presents the results of linear regressions for the year 2016. Robust standard errors are reported (in parentheses)

*Denotes significance at the $10 \%$ level

**At the 5\% level, and

$* * *$ At the $1 \%$ level 
small number of online journals and the fact that there are no print journals as a reference category should be taken into account. The significantly positive coefficients for non-commercial publishers indicate that journals linked to noncommercial publishers perform better than those from commercial publishers (reference category), which confirms our hypothesis H5 and is in line with our descriptive analysis (see Fig. 6).

\section{Discussion and implications}

\subsection{Discussion of the descriptive results}

Our descriptive analysis of the market launch and development of digital services in the field of academic journals reveals that the first journals in our sample began offering digital content in the mid-1990s. Interestingly, we have very few observations of online-only journals, the number of which has not increased significantly over time. This may be due to economic reasons, as most libraries and many institutional customers purchase online and print services. This is the most costly option (Turner 2005), but allows journals to earn twice with the same content or also to price discriminate. Furthermore, our data support the assumption of Davidson (2005) that scientific information is likely to become fully electronic, as not a single journal in our sample has offered print-only services since about 2005. In view of the high costs for customers, an interesting question is to what extent combined print and online services are a long-term business model. In addition to the high costs, reference libraries are losing relevance as a medium for accessing literature (Davidson 2005), which gives reason to assume that the number of onlineonly services will increase in the future.

We find that the group of first movers consists mainly of lower and middle class journals, which supports our hypothesis H1. In line with our hypothesis H2, the later entry of upper class journals does not seem to have been an advantage in the long run, as first movers have been able to improve their performance, especially since the early 2000s and, measured by their impact factor, have almost caught up with the former top performers or, in the case of the followers, have even overtaken them.

According to Laakso et al. (2011), the number of OA publications has increased considerably between 1993 and 2009 and, according to Hanauske et al. (2007), OA publications are read and downloaded more frequently than charged publications. However, our descriptive analysis reveals that journals with charged access perform best over the entire observation period, which is in line with our hypothesis H3 and supports Wang et al. (2019), who doubt a positive influence of OA on journal performance. In our sample, the mean impact factor of journals that offer services without fees and of journals that make only part of their contents freely available have developed similarly over time, whereas pure OA journals have only made up a relatively small subgroup.

An interesting question regarding OA is why established (top) journals have, so far, tended not to offer OA. One possible explanation is that OA challenges the 
foundation of the business model of established journals (Björk 2004), such that the introduction of free services may in many cases be linked to deeper strategic changes. Another aspect is that scholars tend to associate OA journals with rather low prestige and a lack of peer review, although this is not necessarily confirmed in practice (Xia 2010). The danger of losing exclusivity, even if it is only perceived as such, could therefore be a braking factor alongside the strategic heavy-lift. The peer-review process is a crucial element of the (perceived) exclusivity of a journal, and the journal quality might be at risk if publishers are forced to provide OA (Björk et al. 2010; Falagas 2007). If a journal decides to implement OA, it is recommended to make the peer-review process as transparent as possible, as high transparency is associated with high process quality (Wicherts 2016).

Figure 5 supports our hypothesis $\mathrm{H} 4$ and shows that journals which charge general submission fees perform worst. However, there is no clear downward trend, which suggests that the willingness to pay general submission fees for high-level contributions has been low for many years. In contrast, there is a positive trend in the performance of journals that charge fees only for an OA option. Since their performance has developed even better than that of journals not changing any fees, it can be assumed that charging fees for an OA option is a promising business model.

With regard to the journals' publishers, Fig. 6 shows that there have been considerable changes over the years. As we expected in our hypothesis H5 that the best performing journals are not those from commercials publishers, journals from university presses were leading until the early 2000s. Subsequently, journals from non-commercial publishers took the lead and expanded it over time, while journals with the lowest overall performance can be attributed to commercial publishers. Thus, our results show that although large commercial publishers have great market power, this is not reflected in the academic performance of their journals.

\subsection{Discussion of the regression results}

Our regression analysis provides no evidence that $\mathrm{OA}$ is significantly linked to journal performance. This is in line with McCabe and Snyder (2015), according to whom past studies have overestimated the effect of OA. Accordingly, only our descriptive analysis supports hypothesis H3. In our sample for the year 2016, however, we have only 16 journals that charge general submission fees, which we compare with eight OA journals and 152 journals offering only part of their content free of charge. This could limit the reliability of the results, but it at least shows that the uncharged provision of selected journal content seems to be the preferred business model, even though it does not make a meaningful contribution to explaining the (long-term) academic performance.

Our explanatory variable submission fees has general fees as the reference category, against which both journals requiring no submission fees at all or for an OA option perform better. This is in line with our descriptive analysis and supports hypothesis H4. The fact that a large majority of 133 journals demand fees for an OA option limits the reliability of the regression results due to the small comparison groups, but it also shows that this seems to be the preferred option. 
Finally, our regression results show that journals associated with non-commercial publishers perform significantly better than those associated with commercial publishers and university presses. One might have assumed that OA journals and those offering at least selected content free of charge are particularly linked to noncommercial publishers. This, however, cannot be confirmed by our data, as the majority of the 134 journals in these categories are published by commercial publishers.

\subsection{Limitations and implications for further research}

The present study has some limitations, from which implications for future research can be derived. First, relatively little data are available for the first years of the observation period, which affects the robustness of our descriptive results. Accordingly, we recommend conducting studies based on a larger sample, for example by including further disciplines. This leads to a further limitation, as our results may contain discipline-specific effects. With data covering different disciplines, it would be possible to control for corresponding effects in future research projects. However, the literature does not indicate the existence of relevant discipline-specific differences in our research context, so that we assume generalizability, but do not claim it.

Although the illustrations used are probably a good way of showing the evolution of journal performance over time and correlations in the data, it is challenging to take multidimensional influences into account. To control for different influencing factors, we have additionally applied regression analyses. However, their application possibilities are limited in the case of our study, especially since our explanatory variables are time invariant (not by themselves, but because we do not have the relevant data over time). Accordingly, we cannot make any claims about causality, but can only show correlations between the variables of interest. For future studies, we recommend examining more explanatory variables that change over time, including aspects such as the average number of articles per issue and the average number of authors per article. Then, approaches like the regression discontinuity design could be used to look for causal effects.

Furthermore, a weakness can be seen in the measurement of the variable digital services, in which the introduction of digital services was identified based on the conversion of scanned articles to digital formats. There might be cases in which articles were retroactively transferred to digital formats and put online, leading to inaccuracies. To keep distortions to a minimum, we only included observations in which no such indications could be found.

\subsection{Implications for journals}

In spite of the limitations mentioned above (Sect. 4.3), some implications for the strategic management of academic journals can be derived from our investigation. We already know from the existing literature that when submitting academic articles to a journal, scholars pay a particular attention to aspects such as high quality, high visibility, easy accessibility, and a fast publication process (Borgmann 2008; Solomon and Björk 2012). Accordingly, journals should try to optimise 
administrative processes without limiting the quality of the review process. The review process is a relevant quality indicator and should therefore be well founded and transparent. We also know from our research that journals that charge fees for an OA option perform better than those charging general submission fees. To create the financial resources for sound administrative processes while achieving high accessibility and visibility, the introduction of fees for an OA option seems recommendable. Of course, the business model of a journal and the publisher's requirements must be taken into account when considering such measures.

Especially for younger, less established journals, we recommend that they observe the developments of the market, as major shifts have become apparent in the past decades. Amongst these developments is the decreasing use of print journals (Vaughan 2003) and the increasing preference of readers for online journals (Williams et al. 2006). Our study has shown that there are relatively few SSCI-listed online journals, so the market is not yet saturated. We expect that the combined print and online offering of many established journals is a transitional solution as long as the print editions generate revenue or help to maintain a higher reputation.

Finally, even though a large majority of journals are linked to commercial publishers, our study has revealed that the most successful are those from noncommercial publishers. Accordingly, we recommend that new journals in particular do not necessarily concentrate on the large commercial publishers but also consider non-commercial publishers or self-publishing.

\section{Conclusions}

This study examines factors that are related to the citation-based performance of academic journals in the digital age. One contribution is the consideration of the journal level, with which we address limitations of previous studies. Our results reveal that less successful journals were the ones that pioneered the introduction of digital services and have been able to lower the performance gap with their competitors over time. However, our empirical analysis shows no significant correlation between $\mathrm{OA}$ and citation-based performance indicators on the journal level, which contradicts previous studies but is in line with McCabe and Snyder (2015) as well as Wang et al. (2019). Furthermore, our results reveal that journals which do not charge submission fees or only charge for an OA option perform better than journals charging general submission fees. In accordance with our hypothesis $\mathrm{H} 5$, we find that journals from non-commercial publishers perform better than those linked to commercial publishers. Based on our data, we can show that print-only offers are gradually disappearing from the market, whereas combined print and online services seem to have become the standard. Although combined print and online services appear to be a lucrative business for journals and their publishers, the declining relevance of reference libraries as a means for accessing literature puts into question how long this model will work.

Overall, our study provides detailed insights into the digitalisation of academic journals and identifies relevant factors for explaining success in an increasingly digitalised competitive environment. 
Open Access This article is licensed under a Creative Commons Attribution 4.0 International License, which permits use, sharing, adaptation, distribution and reproduction in any medium or format, as long as you give appropriate credit to the original author(s) and the source, provide a link to the Creative Commons licence, and indicate if changes were made. The images or other third party material in this article are included in the article's Creative Commons licence, unless indicated otherwise in a credit line to the material. If material is not included in the article's Creative Commons licence and your intended use is not permitted by statutory regulation or exceeds the permitted use, you will need to obtain permission directly from the copyright holder. To view a copy of this licence, visit http:// creativecommons.org/licenses/by/4.0/.

\section{Appendix}

Table 6 Summary statistics for the 147 journals included in the regressions (year 2016)

\begin{tabular}{|c|c|c|c|c|c|}
\hline & Mean & SD & Min & Max & No journals \\
\hline \multicolumn{6}{|l|}{ Dependent variables } \\
\hline Immediacy index (5-year mean) & 0.35 & 0.24 & 0.03 & 1.39 & 147 \\
\hline Impact factor (5-year mean) & 1.92 & 1.35 & 0.06 & 8.01 & 147 \\
\hline \multicolumn{6}{|l|}{ Explanatory variables } \\
\hline \multicolumn{6}{|l|}{ Access category } \\
\hline No OA & 0.09 & 0.28 & 0 & 1 & 147 \\
\hline OA (general) & 0.05 & 0.21 & 0 & 1 & 147 \\
\hline OA for selected content & 0.86 & 0.34 & 0 & 1 & 147 \\
\hline \multicolumn{6}{|l|}{ Digital services } \\
\hline First mover & 0.08 & 0.27 & 0 & 1 & 147 \\
\hline Follower & 0.53 & 0.50 & 0 & 1 & 147 \\
\hline Late mover & 0.39 & 0.49 & 0 & 1 & 147 \\
\hline First edition (year) & 1984.91 & 16.85 & 1917 & 2012 & 147 \\
\hline \multicolumn{6}{|l|}{ Journal category } \\
\hline Online & 0.03 & 0.18 & 0 & 1 & 147 \\
\hline Online and print & 0.97 & 0.18 & 0 & 1 & 147 \\
\hline \multicolumn{6}{|l|}{ Print } \\
\hline \multicolumn{6}{|l|}{ Publisher category } \\
\hline Commercial publisher & 0.90 & 0.30 & 0 & 1 & 147 \\
\hline Non-commercial publisher & 0.05 & 0.21 & 0 & 1 & 147 \\
\hline University press & 0.05 & 0.23 & 0 & 1 & 147 \\
\hline \multicolumn{6}{|l|}{ Submission fees } \\
\hline No fees & 0.15 & 0.36 & 0 & 1 & 147 \\
\hline General fees & 0.01 & 0.12 & 0 & 1 & 147 \\
\hline Fees for $\mathrm{OA}$ & 0.84 & 0.37 & 0 & 1 & 147 \\
\hline
\end{tabular}




\section{References}

Abramo, Giovanni, Ciriaco A. D’Angelo, and Flavia Di Costa. 2019. The collaboration behavior of top scientists. Scientometrics 118(1):215-232.

Åkesson, Maria, Carsten Sørensen, and Carina Ihlström Eriksson. 2018. Ambidexterity under digitalization: A tale of two decades of new media at a Swedish newspaper. Scandinavian Journal of Management 34 (4): 276-288.

Anderson, Kent, John Sack, Lisa Krauss, and Lori O’Keefe. 2001. Publishing online-only peer-reviewed biomedical literature: Three years of citation, author perception, and usage experience. Journal of Electronic Publishing 6(3).

Asai, Sumiko. 2019. Changes in revenue structure of a leading open access journal publisher: The case of BMC. Scientometrics 121 (1): 53-63.

Atchison, Amy, and Jonathan Bull. 2015. Will open access get me cited? An analysis of the efficacy of open access publishing in political science. PS: Political Science and Politics 48 (1): 129-137.

Ayaita, Adam, Kerstin Pull, and Uschi Backes-Gellner. 2019. You get what you 'pay' for: Academic attention, career incentives and changes in publication portfolios of business and economics researchers. Journal of Business Economics 89 (3): 273-290.

Azar, Ofer H., and David M. Brock. 2008. A citation-based ranking of strategic management journals. Journal of Economics and Management Strategy 17 (3): 781-802.

Bergstrom, Carl T., and Theodore C. Bergstrom. 2004. The costs and benefits of library site licenses to academic journals. Proceedings of the National Academy of Sciences 101 (3): 897-902.

Bergstrom, Theodore C., Paul N. Courant, R. Preston McAfee, and Michael A. Williams. 2014. Evaluating big deal journal bundles. Proceedings of the National Academy of Sciences 111 (26): 9425-9430.

Bernius, Steffen, and Matthias Hanauske. 2009. Open access to scientific literature: Increasing citations as an incentive for authors to make their publications freely accessible. In: Sprague Jr., R. H. (ed.): Proceedings of the 42nd Hawaii International Conference on System Sciences, Los Alamitos (CA).

Beverungen, Armin, Steffen Böhm, and Christopher Land. 2012. The poverty of journal publishing. Organization 19 (6): 929-938.

Björk, Bo-Christer. 2004. Open access to scientific publications: An analysis of the barriers to change? Information Research 9(2). https://informationr.net/ir/9-2/paper170. Accessed 27 December 2019.

Björk, Bo-Christer., Patrik Welling, Mikael Laakso, Peter Majlender, Turid Hedlund, and Gudni Gudnason. 2010. Open access to the scientific journal literature: Situation 2009. PLoS ONE 5 (6): e11273.

Borgman, Christine L. 2008. Data, disciplines, and scholarly publishing. Learned Publishing 21 (1): 29-38.

Borokhovich, Kenneth A., Robert J. Bricker, and Betty J. Simkins. 1999. Financial Management's success as an academic journal. Financial Management 28 (3): 76-82.

Boufarss, Mohamed. 2020. Charting the Open Access scholarly journals landscape in the UAE. Scientometrics 122 (3): 1707-1725.

Boyce, Peter, Donald W. King, Carol Montgomery, and Carol Tenopir. 2004. How electronic journals are changing patterns of use. Serials Librarian 46 (1-2): 121-141.

Brophy, Jan, and David Bawden. 2005. Is Google enough? Comparison of an internet search engine with academic library resources. Aslib Proceedings 57 (6): 498-512.

Chressanthis, George A., and June D. Chressanthis. 1994. The relationship between manuscript submission fees and journal quality. The Serials Librarian 24 (1): 71-86.

Collin, Sven-Olof., Ulf Johansson, Katarina Svensson, and Per-Ola. Ulvenblad. 1996. Market segmentation in scientific publications: Research patterns in American vs European management journals. British Journal of Management 7 (2): 141-154.

Craig, Ian D., Andrew M. Plume, Marie E. McCeigh, James Pringle, and Mayur Amin. 2007. Do open access articles have greater citation impact? A critical review of the literature. Journal of Informetrics 1 (3): 239-248.

Danell, Rickard, Lars Engwall, and Olle Persson. 1997. The first mover and the challenger: The relationship between two journals in organization research. Scientometrics 40 (3): 445-453.

Das, Atin, and Pritha Das. 2006. Delay between online and offline issue of journals: A critical analysis. Library and Information Science Research 28 (3): 453-459. 
Davidson, Lloyd A. 2005. The end of print: Digitization and its consequence-Revolutionary changes in scholarly and social communication and in scientific research. International Journal of Toxicology 24 (1): $25-34$.

de Zepetnek, Steven Tötösy., and Joshua Jia. 2014. Electronic journals, prestige, and the economics of academic journal publishing. CLCWeb Comparative Literature and Culture 14 (1): 1-12.

Dewatripont, Mathias, Victor Ginsburgh, Patrick Legros, and Alexis Walckiers. 2007. Pricing of scientific journals and market power. Journal of the European Economic Association 5 (2-3): 400-410.

Di Gianfranco, Vaio, Daniel Waldenström, and Jacob Weisdorf. 2012. Explorations in Economic History 49 (1): 92-104.

Ding, Waverly W., Sharon G. Levin, Paula E. Stephan, and Anne E. Winkler. 2010. The impact of information technology on academic scientists' productivity and collaboration patterns. Management Science 56 (9): 1439-1461.

Evans, James A. 2008. Electronic publication and the narrowing of science and scholarship. Science 321 (5887): 395-399.

Eysenbach, Günther. 2006. Citation advantage of open access articles. PLoS Biology 4 (5): e157.

Falagas, Matthew E. 2007. Peer review in open access scientific journals. Open Medicine 1 (1): e49-e51.

Fyfe, Aileen, Kelly Coate, Stephen Curry, Stuart Lawson, Noah Moxham, and Camilla Mørk. Røstvik. 2017. Untangling academic publishing: A history of the relationship between commercial interests, academic prestige and the circulation of research. BIROn Birkbeck Institutional Research Online. https://doi.org/10.5281/zenodo.546100.

Gargouri, Yassine, Chawki Hajjem, Vincent Larivière, Yves Gingras, Les Carr, Tim Brody, and Stevan Harnad. 2010. Self-selected or mandated, open access increases citation impact for higher quality research. PLoS ONE 5 (10): 1-12.

Gasparyan, Armen Yuri, Lilit Ayvazyan, and George D. Kitas. 2013. Open access: Changing global science publishing. Croatian Medical Journal 54 (4): 403-406.

Gaulé, Patrick, and Nicolas Maystre. 2011. Getting cited: Does open access help? Research Policy 40 (10): 1332-1338.

González-Pereira, Borja, Vicente P. Guerrero-Bote, and Félix. Moya-Anegón. 2010. A new approach to the metric of journals' scientific prestige: The SJR indicator. Journal of Informetrics 4 (3): 379-391.

Goodrum, Abby A., Katherine W. McCain, Steve Lawrence, and Lee Giles. 2001. Scholarly publishing in the internet age: A citation analysis of computer science literature. Information Processing and Management 37 (5): 661-675.

Groesser, Stefan N. 2012. Dynamics of journal impact factors. Systems Research and Behavioral Science 29 (6): 624-644.

Groote, De., and L. Sandra. 2008. Citation patterns of online and print journals in the digital age. Journal of the Medical Library Association 96 (4): 362-369.

Groote, De., L. Sandra, and J.L. Dorsch. 2001. Online journals: Impact on print journal usage. Bulletin of the Medical Library Association 89 (4): 372-378.

Hanauske, Matthias, Steffen Bernius, and Berndt Dugall. 2007. Quantum game theory and open access publishing. Physica A: Statistical Mechanics and its Applications 382 (2): 650-664.

Heckman, James J., and Sidharth Moktan. 2020. Publishing and promotion in economics: The tyranny of the top five. Journal of Economic Literature 58 (2): 419-470.

Jeon, Doh-Shin., and Jean-Charles. Rochet. 2010. The pricing of academic journals: A two-sided market perspective. American Economic Journal: Microeconomics 2 (2): 222-255.

Klamer, Arjo, and Hendrik P. van Dalen. 2002. Attention and the art of scientific publishing. Journal of Economic Methodology 9 (3): 289-315.

Krell, Frank-Thorsten. 2012. The journal impact factor as a performance indicator. European Science Editing 38 (1): 3-6.

Laakso, Mikael, Patrik Welling, Helena Bukvova, Linus Nyman, Bo-Christer. Björk, and Turid Hedlund. 2011. The development of open access journal publishing from 1993 to 2009. PLoS ONE 6 (6): e20961.

Larivière, Vincent, Stefanie Haustein, and Philippe Mongeon. 2015. The oligopoly of academic publishers in the digital era. PLoS ONE 10 (6): e0127502.

Lawrence, Steve, and C. Lee Giles. 1999. Searching the web: General and scientific information access. IEEE Communications Magazine 37 (1): 116-122.

Lawrence, Steve. 2001. Free online availability substantially increases a paper's impact. Nature 411(6837):521. 
Liebowitz, Stan J. 1985. Copying and indirect appropriability: Photocopying of journals. Journal of Political Economy 93 (5): 945-957.

Lozano, George A., Vincent Larivière, and Yves Gingras. 2012. The weakening relationship between the impact factor and papers' citations in the digital age. Journal of the American Society for Information Science and Technology 63 (11): 2140-2145.

Magri, M.H., and A. Solari. 1996. The SCI Journal Citation Reports: A potential tool for studying journals? Scientrometrics 35 (1): 93-117.

Mahdavi, Mohammad Amin, and Iran Abedi. 2014. Online journals influence amongst Iranian universities. International Journal of Information Science \& Management 12 (1): 23-32.

Marks, Kenneth E., Steven P. Nielsen, H. Craig Petersen, and Peter E. Wagner. 1991. Longitudinal study of scientific journal prices in a research library. College and Research Libraries 52 (2): 125-138.

McCabe, Mark J. 2001. The impact of publisher mergers on journal prices: Theory and evidence. The Serials Librarian 40 (1-2): 157-166.

McCabe, Mark J. 2002. Journal pricing and mergers: A portfolio approach. American Economic Review 92 (1): 259-269.

McCabe, Mark J., and Christopher M. Snyder. 2015. Does online availability increase citations? Theory and evidence from a panel of economics and business journals. Review of Economics and Statistics 97 (1): 144-165.

McGuigan, Glenn S., and Robert D. Russell. 2008. The business of academic publishing: A strategic analysis of the academic journal publishing industry and its impact on the future of scholarly publishing. Electronix Journal of Academic and Special Librarianship 9 (3): 1-5.

Montgomery, Carol Hansen, and Donald W. King. 2002. Comparing library and user related costs of print and electronic journal collections. D-Lib Magazine 8 (10): 1-14.

Mueller-Langer, Frank, and Richard Watt. 2013. Optimal pricing and quality of academic journals and the ambiguous welfare effects of forced open access: A two-sided model. RatSWD Working Paper 223, Berlin.

Newman, Mark EJ.. 2009. The first-mover advantage in scientific publication. Europhysics Letters 86 (6): 68001.

Nicholas, David, Ian Rowlands, Paul Huntington, Hamid R. Jamali, and Patricia Hernández Salazar. 2010. Diversity in the e-journal use and information-seeking behaviour of UK researchers. Journal of Documentation 66 (3): 409-433.

Odlyzko, Andrew. 1998. The economics of electronic journals. Journal of Electronic Publishing. https:// doi.org/10.3998/3336451.0004.106.

Pandita, Ramesh. 2013. Publication distribution of open access journals at continental level: An analysis of directory of open access Journals (DOAJ). International Journal of Digital Library Services 3 (3): $65-83$.

Pinfield, Stephen, Jennifer Salter, and Peter A. Bath. 2017. A "gold-centric" implementation of open access: Hybrid journals, the "total cost of publication", and policy development in the UK and beyond. Journal of the Association for Information Science and Technology 68 (9): 2248-2263.

Sabatier, Mareva, and Barthélemy Chollet. 2017. Is there a first mover advantage in science? Pioneering behavior andscientific production in nanotechnology. Research Policy 46 (2): 522-533.

Schauder, Don. 1994. Electronic publishing of professional articles: Attitudes of academics and implications for the scholarly communication industry. Journal of the American Society for Information Science 45 (2): 73-100.

Schell, Lindsey E., Katy Ginanni, and Benjamin Heet. 2010. Playing the field: Pay-per-view e-journals and e-books. The Serials Librarian 58 (1-4): 87-96.

Schonfeld, Roger C. 2011. What to withdraw? Print collection management in the wake of digitization. The Serials Librarian 60 (1-4): 141-145.

Siar, Janet, Melanie Schaffner, and Karla L. Hahn. 2005. Proliferating pricing models. The Serials Librarian 48 (1-2): 199-213.

Solomon, David J., and Bo-Christer. Björk. 2012. Publication fees in open access publishing: Sources of funding and factors influencing choice of journal. Journal of the American Society for Information Science \& Technology 63 (1): 98-107.

Stuart, Kenyon, Ken Varnum, and Judith Ahronheim. 2015. Measuring journal linking success from a discovery service. Information Technology and Libraries 34 (1): 52-76.

Sugimoto, Cassidy R., Vincent Larivière, Chaoqun Ni, and Blaise Cronin. 2013. Journal acceptance rates: A cross-disciplinary analysis of variablility and relationships with journal measures. Journal of Informetrics 7 (4): 897-906. 
Thelwall, Mike. 2012. Journal impact evaluation: A webometric perspective. Scientometrics 92 (2): 429-441.

Todorov, Radosvet, and Wolfgang Glänzel. 1988. Journal citation measures: A concise review. Journal of Information Science 14 (1): 47-56.

Turner, Rollo. 2005. Hidden costs of e-journals. The Serials Librarian 48 (1-2): 215-228.

van Raan, Anthony F. J. 2005. Fatal attraction: Conceptual and methodological problems in the ranking of universities by bibliometric methods. Scientometrics 62 (1): 133-143.

Vaughan, K.T.L. 2003. Changing use patterns of print journals in the digital age: Impacts of electronic equivalents on print chemistry journal use. Journal of the American Society for Information Science and Technology 54 (12): 1149-1152.

Wang, Mingyang, Jiaqi Zhang, Guangsheng Chen, and Kah-Hin. Chai. 2019. Examining the influence of open access on journals' citation obsolescence by modeling the actual citation process. Scientometrics 119 (3): 1621-1641.

Watson, Roger, Michelle Cleary, Debra Jackson, and Glenn E. Hunt. 2012. Open access and online publishing: A new frontier in nursing? Journal of Advanced Nursing 68 (9): 1905-1908.

Weber, Methew S., and Peter R. Monge. 2017. Industries in turmoil: Driving transformation during periods of disruption. Communication Research 44 (2): 147-176.

Wicherts, Jelte M. 2016. Peer review quality and transparency of the peer-review process in open access and subscription journals. PLoS ONE 11 (1): e0147913.

Williams, Thomas L., J. Michael Lindsay, and Judy F. Burnham. 2006. Online vs. print journals: New challenges for academic medical libraries. Journal of Electronic Resources in Medical Libraries 3 (1): 1-8.

Wineburgh-Freed, Maggie. 2007. Scholarly e-journal pricing models and open access publishing. Journal of Electronic Resources in Medical Libraries 4 (1/2): 15-24.

Xia, Jingfeng. 2010. A longitudinal study of scholars attitudes and behaviours toward open-access journal publishing. Journal of the American Society for Information Science and Technology 61 (3): $615-624$.

Publisher's Note Springer Nature remains neutral with regard to jurisdictional claims in published maps and institutional affiliations. 